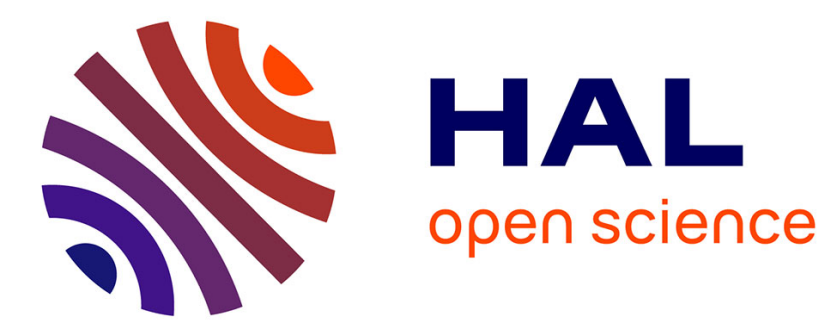

\title{
INTERNAL FRICTION OF GLASSY POLYCARBONATE DURING PLASTIC FLOW
}

\author{
J. Parisot, J. Astier, Arnaud Fernandez, O. Rafi
}

\section{To cite this version:}

J. Parisot, J. Astier, Arnaud Fernandez, O. Rafi. INTERNAL FRICTION OF GLASSY POLYCARBONATE DURING PLASTIC FLOW. Journal de Physique Colloques, 1981, 42 (C5), pp.C5-569-C5574. 10.1051/jphyscol:1981587 . jpa-00221130

\section{HAL Id: jpa-00221130 https://hal.science/jpa-00221130}

Submitted on 1 Jan 1981

HAL is a multi-disciplinary open access archive for the deposit and dissemination of scientific research documents, whether they are published or not. The documents may come from teaching and research institutions in France or abroad, or from public or private research centers.
L'archive ouverte pluridisciplinaire HAL, est destinée au dépôt et à la diffusion de documents scientifiques de niveau recherche, publiés ou non, émanant des établissements d'enseignement et de recherche français ou étrangers, des laboratoires publics ou privés. 


\title{
INTERNAL FRICTION OF GLASSY POLYCARBONATE DURING PLASTIC FLOW
}

\author{
J. Parisot, J. Astier, A. Fernandez and 0 . Rafi \\ Ecole Nationale Supérieure de Mécanique et d'Aérotechnique, Laboratoire de \\ Mécanique et Physique des Matériaux, Equipe de Recherche Associé au C.N.R.S. \\ $n^{\circ} 123,86034$ Poitiers Cedex, France
}

\begin{abstract}
We have measured internal friction of polycarbonate in torsion, during i) a constant strain-rate tensile test ; ii) a differential strain-rate test ; iii) several relaxation tests. We show that internal friction is strongly dependent on strain rate $\dot{\varepsilon}$, but independant on strain and stress. Polycarbonate behaviour shows some analogies with metals : therefore interpretation of the results is based upon the assumption that deformation in due to defects motions. In this view, internal friction can provide means for estimating internal stress.
\end{abstract}

1. Experiment. - Measurements of internal friction were performed during tensile tests, at about $1 \mathrm{~Hz}$, on a torsional pendulum set along the vertical axis of a tensile machine.

The sample, took from a "Makrolon" sheet, presents an initial section of $3 \times 4 \mathrm{~mm}^{2}$ and the initial length actually strained (between heads) is $L_{0} \approx 38 \mathrm{~mm}$. It is fixed between the cross-head of the tensile machine at its lower part, and the inertia bar of the pendulum at its top. The inertia bar is hanged to the load-cell by a strip-iron, the section of which is $30 \times 0.3 \mathrm{~mm}^{2}$.

Torsion motion is recorded by an optical device and damping is measured by a free decay method :

$$
\Delta_{1}=1 / n \log \left(\theta_{0} / \theta_{n}\right)
$$

Internal friction of the sample, $\Delta$, is deduced from $\Delta_{1}$ by the relation /1/ :

$$
\Delta_{1}=\left(1-w_{2} / w_{1}\right) \Delta+w_{2} / w_{1} \Delta_{2}
$$

where $\Delta_{2}$ is the strip-iron damping, measured by replacing the sample by a thin strip-iron, the torque rigidity of which is negligible;

$W_{2}$ and $W_{1}$ are torsional elastic energies respectively stored in the upper strip-iron and in the whole system during an oscillation; it can be seen that $w_{2} / w_{1}=\left(f_{2} / f_{1}\right)^{2}, f_{1}$ being the measured frequen- 
cy of the whole system, and $f_{2}$ the frequency measured in the same conditions as $\Delta_{2} ; f_{2}$ and $\Delta_{2}$ are load-dependent.

\section{Results.}

2.1. - Constant strain-rate tensile test. - Fig. 1 shows the stress curve $a=F / S$ versus time, for an elongation rate $\mathrm{dL} / \mathrm{dt}=0.5 \mathrm{~mm} / \mathrm{mn}$ (that is $\dot{e}=1 / L_{0} \cdot d L / d t=0.22 \cdot 10^{-3} \mathrm{~s}^{-1}$ ).

There are tree parts in this stress curve. The first part (OA) corresponds to a recoverable and homogeneous deformation : internal friction increases from $\Delta=30.10^{-3}$ before loading, to $\Delta_{A}=120.10^{-3}$.

The second part (A B) is a Piobert-Liders plateau with $a_{L}=50 \mathrm{MPa}$. Plastic straining $\left(e_{L} \simeq 55 \%\right)$ is localized on one or two fronts which move along the sample. This heterogeneity of the deformation makes difficult the analysis of internal friction measurements in this part of the tensile curve.

The third part of the curve (B C) corresponds to a homogeneous deformation up to the rupture which occurs by crack-propagation $\left(e_{R}=93 \%\right)$. Internal friction increases from $\Delta_{B}=110.10^{-3}$ to $\Delta_{\mathrm{C}}=200 \cdot 10^{-3}$.

2.2. Differential strain-rate tensile test. - The curve stress vs time of the fig. 2 a has been obtained by taking turns with two strain rates : 0.5 and $0.05 \mathrm{~mm} / \mathrm{mn}$. The part $B$ C of the curve shows stress

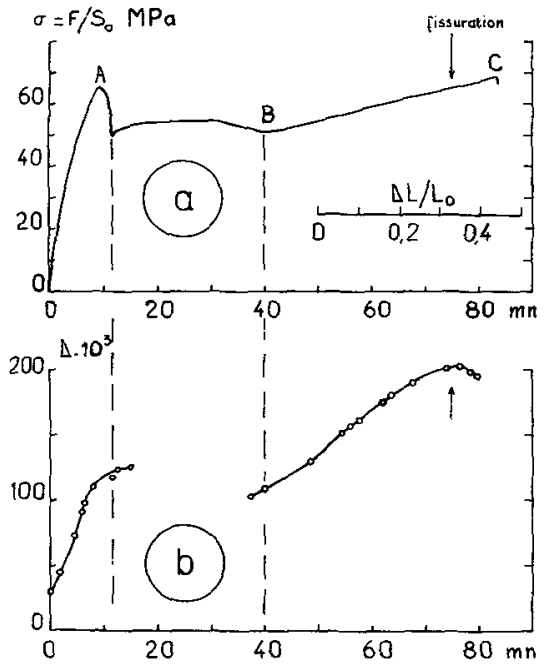

Fig.1

a) Tensile curve. : stress vs time (Strain-rate $\dot{L}=0.5 \mathrm{~mm} / \mathrm{mm}$ )

b) Internal friction

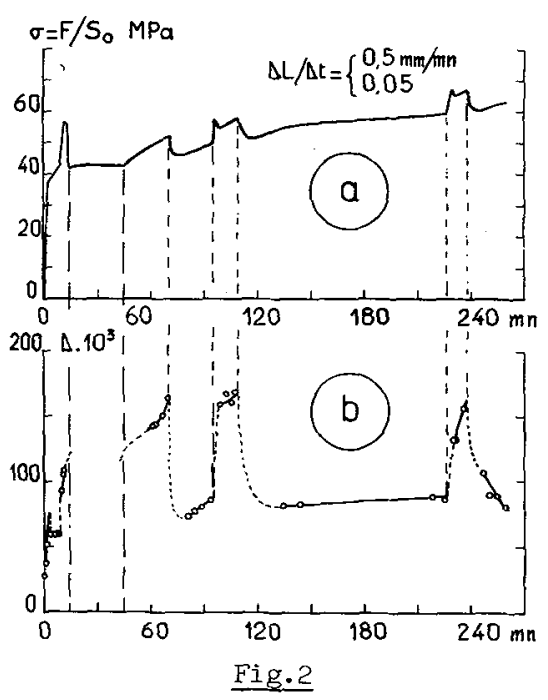

Influence of strain-rate

a) on the stress

b) on the intemal friction. 
drops $\delta o=8.3 \mathrm{MPa}$. Fig. $2 \mathrm{~b}$ shows the drops of internal friction corresponding with strain-rate decreases. Theses drops are important in the $B C$ part of the stress curve ( $\delta \Delta=100.10^{-3}$ for the first of them) ; they also exist in the OA part.

When the strain rate is increased again, the stress-curve shows a transient increase $\delta \sigma$ as in metals subject to aging effects. Then in-ternal friction does not immediately reach the steady-state value as measured in the initial constant strain-rate conditions.

2.3. Stress-Relaxation tests. - The tensile straining test is suddenly stopped at the stress $\sigma_{0}(=58 \mathrm{MPa})$, corresponding to a deformation $e_{0}(=66 \%)$. There are three possibilities.

i) The cross-head is kept immobile. Under the action of the stress $\sigma_{0}$ the specimen continues to elongate very slowly, and the stress decreases following a logarithmic function of time : that is the relaxation (Fig. 3a). During the decrease of $\sigma$, the internal friction decreases also and tends towards a limit close to its initial value measured on the strained material (Fig. 3b).

ii) The cross-head is rapidly moved back and is stopped as the stress is zero. Then the specimen contracts with a decreasing strain rate $\dot{\varepsilon}$ and the stress increases, $\dot{\sigma}>0$ : that is the anti-relaxation (Fig. 4a). The internal friction is immediatly reduced, then it decreases with time as $\dot{\sigma}$, tending again towards its initial value (Fig. 4b).
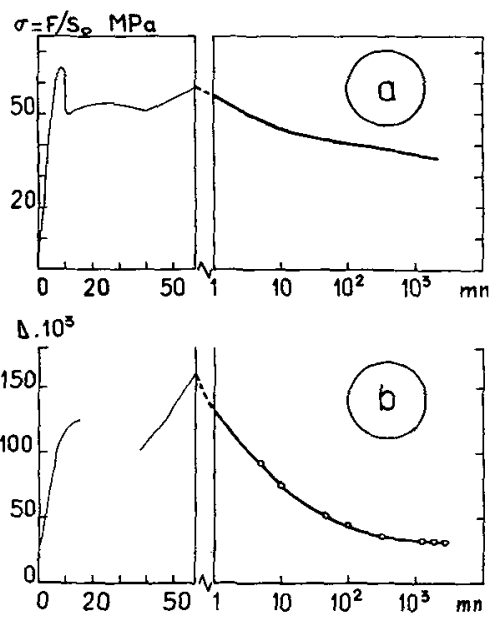

Fig.3

Evolution of the Internal Friction (b) during stress-relaxation (a).
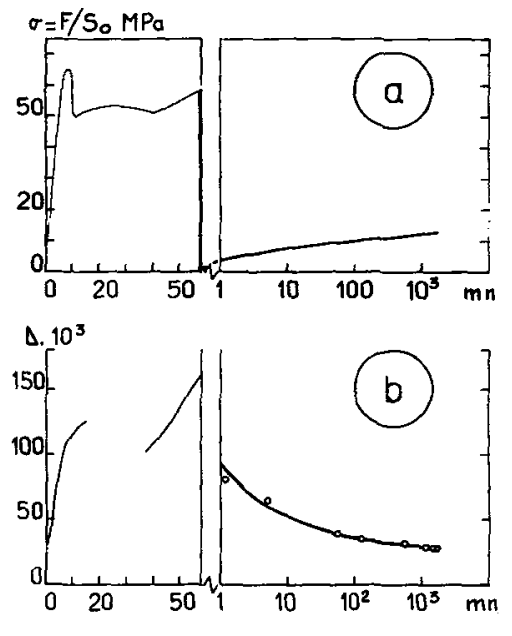

Fig.4

Evolution of the Internal Friction (b) during antirelaxation after total unloading (a). 
iii) The third possibility is to move back the cross-head and stop it after a partial unloading at a stress $\sigma_{0}^{\prime}<\sigma_{0}$. For the upper values of $\sigma_{0}^{\prime}, \dot{\sigma}$ is negative; for the lower values of $\sigma_{0}^{\prime}$, $\dot{\sigma}$ is positive (fig. 5a). There is a value of $\sigma^{\prime}$ ofor which $\dot{\sigma}$ is zero, this stress is usually considered as the internal stress.

Just after this partial unloading the value of internal friction is reduced (Fig. 5b). The instantaneous values of internal friction are plotted versus $\sigma:$ in figure 6 . From this figure it is clear that i) the instantaneous value of $\Delta$ is always higher than its value before straining, $30.10^{-3}$; ii) the curve shows a minimum of $\Delta$ for the stress $\sigma_{0}^{\prime}=20 \mathrm{MPa}$, this stress is smaller than the stress for which $\dot{\sigma}$ is zero : $45 \mathrm{MPa}$.

Discussion. - Internal friction of the unloaded specimen, $\Delta=30.10^{3}$, corresponds to the background between the two transitions $\alpha$ and $\beta$ of the polycarbonate which are respectively at $150{ }^{\circ} \mathrm{C}$ and $-100{ }^{\circ} \mathrm{C}$ for $1 \mathrm{~Hz} / 2 /$. The increase of internal friction observed during strain
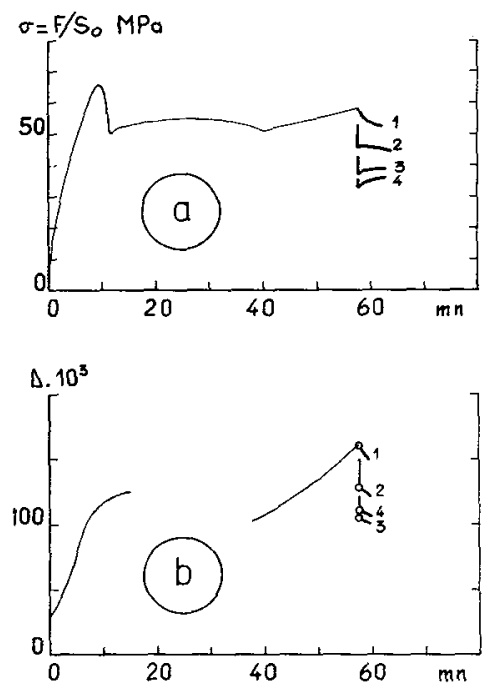

Fig. 5

a) Beginning of the relaxation after partial unloading

b) Correspondent values of the Internal Friction.
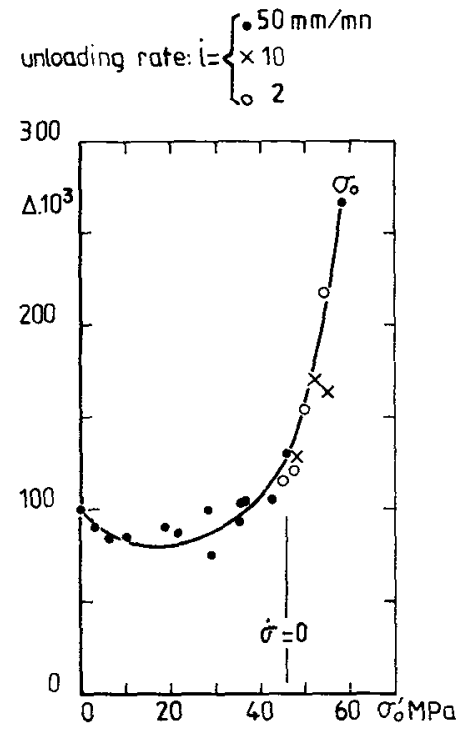

Fig. 6

Internal Friction vs stress immediately after partial unloading. 
does not seem to be related to these transitions but more likely it is connected to the strain rate $\dot{\varepsilon}$. This is clearly observed on the differential strain rate test (Fig. 2) and on the relaxation and anti-relaxation tests : each time $\Delta$ decreases with $\dot{\varepsilon}$. In the relaxation and antirelaxation tests, the same time is necessary for $\dot{\varepsilon}$ being close to zero and for $\Delta$ reaching again its initial value. The same result has been obtained on a specimen strained up to rupture and kept at room temperature for $48 \mathrm{H}$ : it shows the same damping spectrum as undeformed material from 77 to $370 \mathrm{~K}$.

It can be seen from the present results that the strain behaviour of polycarbonate shows several analogies with metals : strainrate sensitivity, existence of an internal stress and existence of an activation volume which has been calculated ( $\simeq 1000 \stackrel{\circ}{\AA}$ ) both from differential strain-rate tests and from relaxation tests.

Those analogies suggest two assumptions. Firstly, the plastic straining of glassy-state polycarbonate is made possible by creation and motion of defects /3/. Secondly, when those defects are moving under the action of the tensile stress, their motion can be modified by a small torque : this modification is dissipating energy, so that it produces internal friction when the torque is sinusoidal.

Using those two assumptions, a coherent interpretation of the results can be given. In all the tests, a strain-rate decrease is related to an internal friction decrease (Fig. 2,3,4) : so the number of the mobile defects also decreases.

The motion of each defect in the material is opposed by the internal stresses. So, the effective stress acting on a defect is: $\sigma_{e}=\sigma-\sigma_{i}$ where $\sigma$ is the external applied stress, and $\sigma_{i}$ is the internal stress.Consequently when applying an external stress $\sigma=\sigma_{i}$, the effective stress $\sigma_{e}$ becomes zero and the plastic strain-rate is also zero.

In the relaxation test, defects continue to move as Iong as $\sigma_{e}>0$, but because the sample length increases, the stress decreases and the plastic strain rate $\dot{\varepsilon}_{\mathrm{P}}$ also; as the defects are less and less mobile, the internal friction also decreases (Fig. 3). In the antirelaxation test, for $\sigma=0$, the effective stress is $\sigma_{e}=-\sigma_{i}$; that stress induces the backward motion of some defects and macroscopically, the strain rate $\dot{\varepsilon}_{B}$ is negative; the internal friction $\Delta$ is not sensitive to the direction of the displacement of the defects, and decreases with $\dot{\varepsilon}_{B}$.

In the partial unloading test, those two effects are in competition : the whole strain-rate is $\dot{\varepsilon}=\dot{\varepsilon}_{P}+\dot{\varepsilon}_{B}$. As schematically shown in fig. 7a, $\dot{\varepsilon}_{\mathrm{P}}$ and $\dot{\varepsilon}_{\mathrm{B}}$ are respectively function of the stress $\sigma_{0}^{\prime}$ ap- 
plied after unloading. When applying a stress $\sigma_{0}=\sigma_{i}$, the plastic strain $\dot{\varepsilon}_{\mathrm{P}}$ becomes zero and the total strain rate $\dot{\varepsilon}$ is $\dot{\varepsilon}=\dot{\varepsilon}_{\mathrm{B}}<0$. But the internal friction $\Delta$ varies as ${ }^{{ }} \varepsilon_{P}+\left|\dot{\varepsilon}_{B}\right|$ : consequently, it passes through a minimum when $\dot{\varepsilon}_{P}$ becomes zero (Fig. $7 \mathrm{~b}$ ) and the corresponding value of the applied stress (Fig. 6) is the macroscopic value of the internal stress $\sigma_{i}$. That value is less than the stress for which $\dot{\sigma}=0$, corresponding to a transient equilibrium between the plastic strain-rate and the backward strain-rate : $\dot{\varepsilon}_{\mathrm{P}}+\dot{\varepsilon}_{\mathrm{B}}=0$ (sample 2 on fig. 5a).
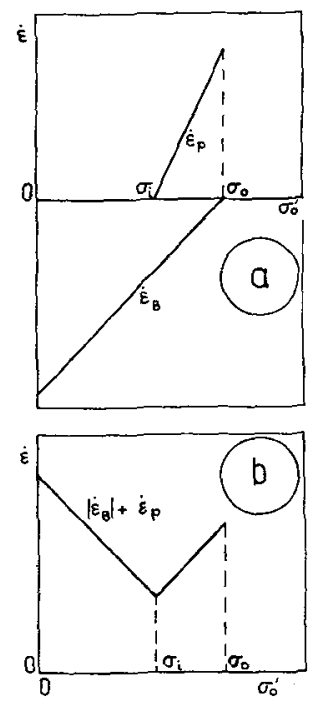

Fig.7
a) Schematic drawing of $\dot{\varepsilon}_{P}$ and $\dot{\varepsilon}_{B}$ vs the stress immediately after unloading
b) $\dot{\varepsilon}_{P}+\left|\dot{\varepsilon}_{B}\right|$

4. Aknowledgements. - The authors are grateful to $P^{r}$. B. Escaig and $D^{r}$. J.L. Gacougnolle for helpful discussions and assistance for writing the paper.

5. References.

/1/ G. COLLETTE - C.R. Hebd. Séances Acad. Sci. B 246, 2756, (1958) Métaux Corros. Ind. 40,143 , (1964).

/2/ N.G. MC CRUM, B.E. READ and G. WILLIAMS, Anelastic and Dielectric Effects in Polymeric Solids. John WILEY and SONS, London.

$/ 3 /$ B. ESCAIG.

Dislocations et déformation plastique pp.261-286.

Ecole d'Eté d'Yravals 1979.

P. GROH, L.P. KUBIN, J.L. MARTIN, éditeurs.

Editions de Physique - Paris. 